\title{
KANDUNGAN GULA TEREDUKSI DAN VITAMIN C DALAM BUAH PISANG NANGKA (Musa paradisiaca forma typica) SETELAH PEMERAMAN DENGAN ETHREL DAN DAUN TANAMAN
}

\section{REDUCINGSUGAR CONTENTAND VITAMINE C IN BANANA (Musa paradisiaca forma typica)AFTER CURING BY ETHREL AND PLANT LEAVES}

\author{
${ }^{1 *}$ Ni Putu Harta Diani Pande, ${ }^{2}$ Made Ria Defiani dan ${ }^{3}$ Ni Luh Arpiwi \\ 1,2,3 Prodi Biologi, Fakultas MIPA, Universitas Udayana, Bali. \\ *Email:dianipande2@gmail.com
}

\section{INTISARI}

Pisang nangka merupakan salah satu jenis pisang yang dapat dijadikan produk olahan. Lama waktu matang yang relatif lebih panjang menyebabkan ketersediaan pisang nangka terbatas. Pemeraman baik secara alami maupun kimiawi dapat dilakukan dan tingkat kematangan pisang ditentukan melalui penampakan morfologi dan analisis kimiawi. unEksplorasi dilakukan dengan pemanfaatan daun gamal, daun kakao, daun pisang dan etilen serta lama waktu pemeraman terhadap tingkat kematanganbuah,kandungan vitamin $\mathrm{C}$ dan kadar gula tereduksi. Metode Rancangan Acak Lengkap (RAL) dengan 2 faktor, yaitu lama pemeraman dengan 3 perlakuan yaitu L1 (pemeraman selama 3 hari), L2 (pemeraman selama 6 hari) dan L3 (pemeraman selama 9 hari) dan cara pemeraman yang digunakan yaitu C0 (kontrol), $\mathrm{C} 1$ (pemeraman dengan etilen 0,5\%), C2 (Pemeraman dengan daun pisang), C3 (pemeraman dengan daun gamal) dan C4 (pemeraman dengan daun kakao) digunakan dalam penelitian. Masing - masing kombinasi perlakuan diulang 4 kali dengan 3 unit percobaan. Hasil penelitian menunjukkan cara pemeraman menggunakan daun kakao dan etilen $0,5 \%$ mempengaruhi kematangan buah pisang nangka. Etilen $0,5 \%$ dapat meningkatkan skor tingkat kematangan buah dan vitamin C. Daun kakao berpengaruh pada peningkatan skor kematangan buah, kadar gula tereduksi dan kandungan vitamin C. Semakin lama pemeraman dapat meningkatkan skor pematangan buah pisang nangka dan meningkatkan kadar gula tereduksi.

Kata kunci : Pisang nangka, etilen, daun kakao, daun pisang, daun gamal

\section{ABSTRACT}

Musa paradisiaca forma typica is one type of banana that can be used as a processed product. Its ripening time relatively longer than other bananas and the availability is limited. One way to accelerate the availability of banana is by treating it naturaly and chemical. How to do in determining the ripeness of bananas as morphological and chemical analysis. The objectives of this study were to explore the utilization of Gliricidia sepium leaf, cocoa leaf, banana leaf and ethylene and the duration of treatment to the maturity level of Musa paradisiaca forma typica, vitamin C, vitamin A, reducing sugar content as well as ripening time and rotting. Completely Randomized Design was used with 2 factors, the duration of curing with 3 treatments ie L1 (curing for 3 days), L2 (curing for 6 days) and L3 (curing for 9 days) and type of calibration method used was C0 (control), C1 (curing with ethylene 0,5\%), C2 (curing with banana leaf), C3 (curing with Gliricidia sepium leaf) and C4 (curing with cocoa leaf) . Each treatment combination was repeated 4 times with 3 experimental units. The results showed that curing with cocoa leaves and $0.5 \%$ ethylene affected banana maturity. Ethylene $(0.5 \%)$ increase the maturation score and vitamin C. Cocoa increased maturation score, reducing sugar and vitamin $\mathrm{C}$ content. The longer the curing the more increase the maturation score and increase the reducing sugar content.

Keywords: Musa paradisiaca forma typica, ethylene, cocoa leaf, banana leaf, G. sepium leaf

\section{PENDAHULUAN}

Salah satu buah lokal Indonesia yang dapat dijadikan berbagai makanan olahan adalah pisang. Selain sebagai bahan olahan, pisang juga dapat dimakan secara langsung sebagai buah segar (Siagian, 2009). Saat ini, kultivarpisang nangka sering digunakan sebagai makanan olahan. Ukuran buah pisang nangka relatif besar dan setiap tandan memiliki buah yang cukup banyak yaitu rata - rata $15-20$ buah per sisir. (Prabawati dkk., 2008).

Pisang nangka merupakan salah satu jenis pisang plantain dimana dapat dimakan jika sudah diolah terlebih dahulu sebagai bahan baku pisang goreng dan kolak. Pisang nangka memiliki buah yang cukup besar dan panjang seperti pisang tanduk. Keunggulan pisang nangka adalah dapat memproduksi banyak buah pada setiap tandan (Prabawati dkk.,2008). Kulit buah yang cukup tebal menjadi kendala pada saat pemasakan pisang nangka sehingga diperlukan waktu yang cukup lama .

Kematangan pisang yang seragam dapat diperoleh dengan pemberian etilen secara eksogen (Kader, 2002).Menurut Zuhairini (1997), teknik pemeraman dengan material yang berbeda perlu dilakukan secara konvensional seperti pemanfaatan dedauan atau pengasapan. Teknik pemeraman dedaunan dilakukan dengan beberapa jenis daun seperti daun gamal, daun albizia, daun pisang dan daun lamtoro (Utami dkk., 2014).

Penelitian menggunakan daun gamal, daun pisang dan daun kakao. Daun gamal digunakan karena ketersediaannya yang melimpah dan ekstrak daun gamal sudah pernah digunakan dalam pematangan pisang Ambon (Yulianingsih dan Dasuki, 1989). Daun pisang juga digunakan sebagai bahan pemeram di pedesaan. Akhir - akhir ini daun kakao juga banyak digunakan sebagai pemeram alami oleh masyarakat Desa Pangsan, karena sebelumnya kulit kakao telah diteliti dapat memasakkan pisang secara cepat. Dedaunan kakao yang tua agar tidak menjadi limbah digunakan untuk pemeraman pisang.

\section{MATERI DAN METODE}

Penelitian dilakukan dalam 2 tahap yaitu tahap pemeraman dilakukan di Desa Pangsan, Kec.Petang, Kab. Badung dan tahap analisis kandungan dilakukan di Lab. Analisis FTP Unud. Metode yang digunakan adalah Rancangan Acak Lengkap (RAL) dengan 2 faktor, yaitu faktor 1 adalah 
lama pemeraman dengan 3 perlakuan yaitu L1 (pemeraman selama 3 hari), L2 (pemeraman selama 6 hari) dan L3 (pemeraman selama 9 hari). Faktor kedua yaitu cara pemeraman yang digunakan yaitu C0 (kontrol), C1 (pemeraman dengan etilen 0,5\%), $\mathrm{C} 2$ (Pemeraman dengan daun pisang), C3 (pemeraman dengan daun gamal) dan $\mathrm{C} 4$ (pemeraman dengan daun kakao). Etilen yang digunakan adalah ethel Masing - masing kombinasi perlakuan dilakukan dengan 4 kali ulangan dengan 3 unit.

Tahap pertama yaitu buah pisang nangka dipanen kurang lebih setelah 90 hari. Kemudian setelah 1 hari dilakukan perlakuan pemeraman buah. Suhu yang digunakan pada penelitian ini adalah $30-32^{\circ} \mathrm{C}$. Perlakuan $\mathrm{C} 1$ yaitu pisang dicelupkan 1 menit pada etilen $0,5 \%$ dan dikeringanginkan. Perlakuan $\mathrm{C} 2$ pisang dibungkus daun pisang, pisang dibungkus daun gamal (C3), pisang dibungkus daun kakao (C4), dan pisang tanpa perlakuan (kontrol $=\mathrm{C} 0$ ). Penggunaan perlakuan daun ditimbang yaitu $20 \%$ dari bobot masing - masing buah pisang yang akan diperam. Setelah perlakuan, buah dibungkus dengan koran Colour chart (Tabel 1) digunakan untuk menentukan tingkat kematangan buah pisang (warna kulit buah dan tekstur daging buah) dengan skor.

Tabel 1. Deskripsi skor kematangan berdasarkan indeks warna kulit dan tekstur buah pisang nangka (colour chart)

\begin{tabular}{|c|c|c|c|}
\hline $\begin{array}{c}\text { Tingkat } \\
\text { kematangan }\end{array}$ & $\begin{array}{c}\text { Warna kulit } \\
\text { buah }\end{array}$ & $\begin{array}{c}\text { Daging } \\
\text { buah }\end{array}$ & Gambar \\
\hline 1 & $\begin{array}{c}\text { Seluruhnya } \\
\text { berwarna hijau }\end{array}$ & Keras & \\
\hline 2 & $\begin{array}{l}\text { Hijau lebih } \\
\text { banyak dari } \\
\text { Kuning }\end{array}$ & Keras & \\
\hline 3 & $\begin{array}{c}\text { Kuning lebih } \\
\text { banyak dari } \\
\text { hijau }\end{array}$ & $\begin{array}{c}\text { Mulai } \\
\text { melunak }\end{array}$ & \\
\hline 4 & $\begin{array}{c}\text { Hampir } \\
\text { keseluruhan } \\
\text { berwarna } \\
\text { kuning }\end{array}$ & Lunak & \\
\hline 5 & $\begin{array}{l}\text { Kuning } \\
\text { dengan bintik } \\
\text { coklat }\end{array}$ & $\begin{array}{l}\text { Sangat } \\
\text { lunak }\end{array}$ & \\
\hline 6 & $\begin{array}{c}\text { Kuning } \\
\text { kecoklatan }\end{array}$ & $\begin{array}{l}\text { Sangat } \\
\text { lunak, } \\
\text { mulai } \\
\text { berair }\end{array}$ & \\
\hline
\end{tabular}

Tahap kedua yaitu analisis kimiawi kandungan buah. Analisis gula reduksi dilakukan dengan metode Smogy Nelson dan analisis kandungan vitamin $\mathrm{C}$ dengan metode Titrasi Iodiometri. Sampel yang digunakan adalah buah pisang yang diambil pada hari ke-3, ke-6 dan ke-9 dengan ulangan 3 kali.Data kuantitatif dianalisis dengan uji varian (Two Way ANOVA) dengan menggunakan software SPSS versi 23.Untuk mengetahui pengaruh cara pemeraman, lama pemeraman dan interaksi antar perlakuan dilakukan uji lanjutan yaitu uji Duncan Multiple Range Test (DMRT).

\section{HASIL}

\section{Tingkat Kematangan Buah}

Tingkat kematangan buah pisang ditunjukkan dengan menggunakan skor pada colour chart, pada hari ke-3, ke 6 dan ke 9 yang ditunjukkan pada Tabel 2.

Tabel 2. Skor tingkat kematangan buah pisang nangka dengan cara pemeraman yang berbeda

\begin{tabular}{lccc}
\hline \multirow{2}{*}{ Perlakuan } & \multicolumn{3}{c}{$\begin{array}{c}\text { Skor tingkat kematangan dengan lama } \\
\text { pemeraman (hari) }\end{array}$} \\
\cline { 2 - 4 } & $3(\mathrm{~L} 1)$ & $6(\mathrm{~L} 2)$ & $9(\mathrm{~L} 3)$ \\
\hline Kontrol (C0) & $1.72^{\mathrm{a}}$ & $3.81^{\mathrm{b}}$ & $5.97^{\mathrm{a}}$ \\
Etilen 0,5\% (C1) & $1.75^{\mathrm{a}}$ & $4.06^{\mathrm{a}}$ & $6.00^{\mathrm{a}}$ \\
Daun pisang (C2) & $1.28^{\mathrm{b}}$ & $3.53^{\mathrm{c}}$ & $5.36^{\mathrm{b}}$ \\
Daun gamal (C3) & $1.00^{\mathrm{c}}$ & $3.00^{\mathrm{d}}$ & $5.14^{\mathrm{b}}$ \\
Daun kakao (C4) & $1.56^{\mathrm{a}}$ & $3.89^{\mathrm{ab}}$ & $5.89^{\mathrm{a}}$ \\
\hline
\end{tabular}

Keterangan: Huruf yang berbeda pada kolom yang sama menunjukkan berbeda nyata pada taraf $5 \%$. 


\section{Kadar Gula Tereduksi}

Kadar gula tereduksi pada buah pisang nangka menunjukkan adanya interaksi antara cara dan lama pemeraman berbeda berpengaruh nyata, ditunjukkan pada Tabel 3.

\section{Kandungan Vitamin C}

Hasil analisis statistik menunjukkan interaksi antara lama pemeraman dan cara pemeraman tidak berpengaruh nyata, namun masing - masing perlakuan memberikan pengaruh nyata terhadap kandungan vitamin $\mathrm{C}$ pada buah pisang nangka.
Kandungan vitamin $\mathrm{C}$ pada buah pisang nangka terhadap cara pemeraman dapat ditunjukkan pada Gambar 1, sedangkan pengaruh lama pemeraman dapat ditunjukkan pada Gambar 2.

Berdasarkan Gambar 1 cara pemeraman berpengaruh nyata terhadap kandungan vitamin $\mathrm{C}$. Kandungan vitamin $\mathrm{C}$ pada kontrol sebanyak $29,04 \mathrm{mg} / 100 \mathrm{~g}$ berbeda nyata dengan pemeraman menggunakan etilen $0,5 \%$ dan daun kakao masing - masing sebanyak $74,56 \mathrm{mg} / 100 \mathrm{~g}$ dan $67,55 \mathrm{mg} / 100 \mathrm{~g}$. pemeraman daun pisang sebesar $23,11 \mathrm{mg} / 100 \mathrm{~g}$ dan daun gamal sebesar $24,93 \mathrm{mg} / 100 \mathrm{~g}$ tidak berbeda nyata dengan kontrol.

Tabel 3. Kadar gula tereduksi buah pisang nangka terhadap cara pemeraman dan lama pemeraman yang berbeda

\begin{tabular}{cccc}
\hline \multirow{2}{*}{ Perlakuan } & \multicolumn{3}{c}{ Kadar gula tereduksi (\%gula total) hari ke- } \\
\cline { 2 - 4 } & 3 & 6 & 9 \\
\hline Kontrol & $115,36^{\mathrm{h}}$ & $198,82^{\text {de }}$ & $291,92^{\mathrm{b}}$ \\
Etilen 0,5\% & $186,77^{\text {ef }}$ & $272,93^{\text {bc }}$ & $374,99^{\text {a }}$ \\
Daun pisang & $163,41^{\text {efg }}$ & $176,09^{\text {ef }}$ & $288,89^{\mathrm{b}}$ \\
Daun gamal & $122,68^{\text {gh }}$ & $149,71^{\text {fgh }}$ & $233,75^{\text {cd }}$ \\
Daun kakao & $204,39^{\text {de }}$ & $308,04^{\mathrm{b}}$ & $410,66^{\text {a }}$ \\
\hline
\end{tabular}

Keterangan: Huruf yang berbeda pada baris dan kolom yang samamenunjukkan berbeda nyata pada taraf $5 \%$.

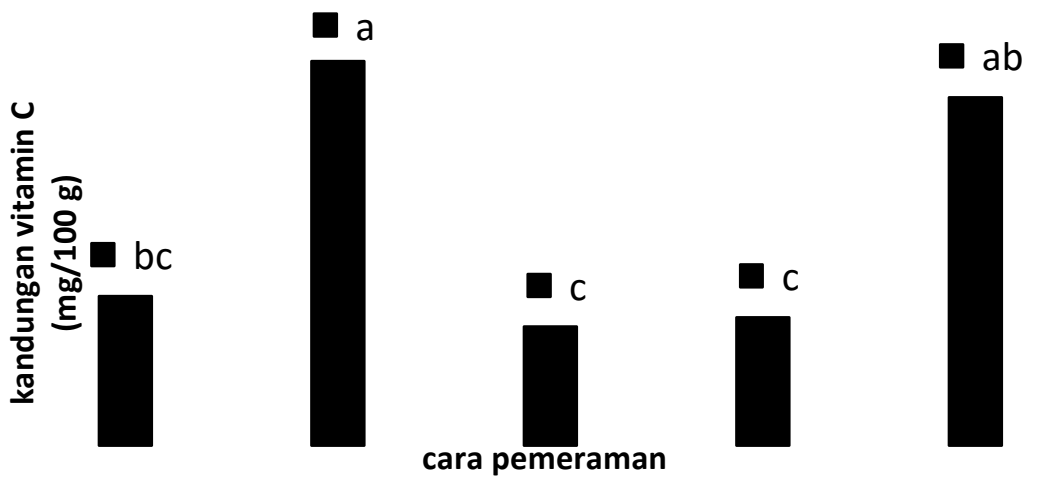

Gambar 1. Kandungan vitamin $\mathrm{C}$ pada buah pisang nangka dengan perlakuan cara pemeraman berbeda. Huruf yang berbeda menunjukkan berbeda nyata pada $\alpha=5 \%$

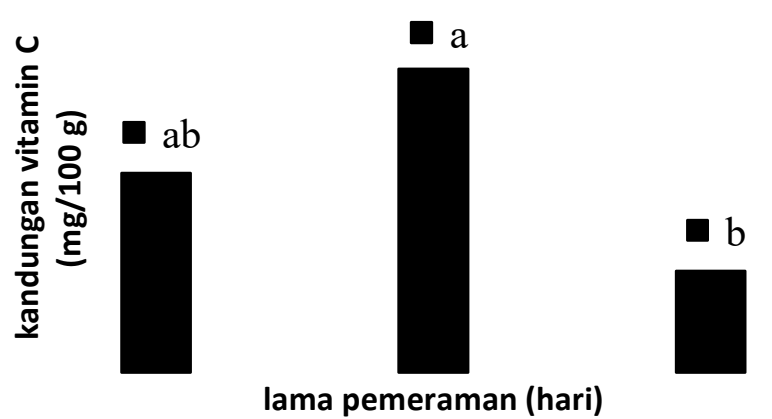

Gambar 2. Kandungan vitamin $\mathrm{C}$ pada buah pisang nangka dengan perlakuan lama pemeraman berbeda. Huruf yang berbeda menunjukkan berbeda nyata pada $\alpha=5 \%$

Gambar 2 menunjukkan kandungan vitamin $\mathrm{C}$ pada buah pisang nangka selama pemeraman 3 hari sebesar 43,39 $\mathrm{mg} / 100 \mathrm{~g}$ yang tidak berbeda nyata dengan perlakuan lainnya. Kandungan vitamin $\mathrm{C}$ dengan lama pemeraman 6 hari yaitu $66,01 \mathrm{mg} / 100 \mathrm{~g}$ dan pemeraman selama 9 hari sebesar 22,11 $\mathrm{mg} / 100 \mathrm{~g}$.

\section{PEMBAHASAN}

\section{Tingkat Kematangan Buah}

Hasil penelitian menunjukkan adanya peningkatan skor kematangan buah pisang nangka (Tabel 2). Hari ke-3 mengindikasikan warna kulit buah pisang menjadi hijau yang lebih dominan daripada kuning yaitu hampir mencapai skor 2 (dua). Skor kematangan pada hari ke-6 sudah menunjukkan kematangan yang baik yaitu warna kulit buah hampir keseluruhan berwarna kuning (skor 4). Hari ke-9 terlihat bahwa pisang sudah mengalami pembusukan, seperti pada pisang yang diberi perlakuan etilen $0,5 \%$, daun kakao dan kontrol. Buah pisang yang sudah matang berwarna kuning. Hal ini 
disebabkan adanya penurunan klorofil sebagai pigmen utama dan peningkatan karotenoid selama proses pemeraman terjadi seperti pada mangga harum manis dan mangga manalagi (Dewi, 2010). Laju respirasi yang lambat akan menghambat aktivitas enzimatik pada pisang seperti yang terjadi pada penelitian Siagian (2009) mengenai pisang barangan.

Daun kakao yang menunjukkan tingkat kematangan yang signifikan daripada pemeraman menggunakan daun gamal dan daun pisang, berhubungan dengan struktur masing - masing daun. Umumnya tanaman kakao memiliki serat kasar yang tinggi sehingga susah terdekomposisi (Rahim dkk., 2015). Kerapatan struktur daun yang tinggi pada daun kakao menyebabkan suhu saat pemeraman dapat bertahan lebih lama. Sedangkan pada daun gamal dan daun pisang merupakan dedaunan yang mudah terurai sehingga dimanfaatkan sebagai pakan ternak (Wina, 2001).

\section{Kadar Gula Tereduksi}

Interaksi antara cara dan lama pemeraman mempengaruhi kadar gula tereduksi. Kadar gula tereduksi meningkat pada masing - masing perlakuan cara peram(Tabel 3). Buah pisang akan mengalami peningkatan kadar gula seiring dengan meningkatnya respirasi akibat perombakan pati yang terjadi. Menurut Mahapatra dkk. (2010), saat proses pematangan terjadi maka kandungan pati pada buah pisang yang masih mentah $20-30 \%$ dan pada pisang yang sudah masak mencapai hingga 1-2\%. Kandungan gula pada buah pisang akan meningkat pada pisang mentah $1-2 \%$ sedangkan pada pisang masak mencapai $15-20 \%$.

Kombinasi yang menghasilkan kadar gula tereduksi tertinggi adalah cara pemeraman daun kakao dengan lama pemeraman 9 hari. Hal ini disebabkan oleh enzim penolitik pada hari ke -9 belum banyak mengubah gula tereduksi menjadi senyawa lain (Anam, 2011). Penggunaan dedaunan dapat menghasilkan $\mathrm{CO}_{2}$ yang tinggi. Kandungan $\mathrm{CO}_{2}$ yang yang tinggi akan berpengaruh pada reaksi pematangan yang berjalan lambat dan juga akan berpengaruh pada suhu peyimpanan yang rendah. Suhu yang rendah akan memperlambat proses - proses biokimia (Apandi, 1984). Kombinasi perlakuan yang menghasilkan kadar gula tereduksi paling rendah adalah cara pemeraman kontrol selama 3 hari.

Pemecahan polisakarida berupa amilum (zat pati) menjadi disakarida (sukrosa) dan monosakarida berupa gula tereduksi (glukosa dan fruktosa) terjadi saat respirasi dibantu oleh enzim amilase. Enzim amilase berperan dalam peningkatan kadar gula tereduksi pada pisang saat proses pematangan (Pujimulyani, 2009). Selain itu karbohidrat dalam bentuk selulosa yang dibantu oleh enzim selulase dan selobiase akan mendegradasi dinding sel menjadi bentuk yang sederhana hingga menjadi glukosa (Fitriningrum dkk., 2013). Meningkatnya kandungan selulosa akan memberikan rasa manis pada buah pisang dan berpengaruh pada menurunnya zat - zat fenolik yang menyebabkan rasa sepet (Anam, 2011).

\section{Kandungan Vitamin C}

Cara peram menggunakan etilen $0,5 \%$ menghasilkan kandungan vitamin $\mathrm{C}$ yang paling tinggi (Gambar 1). Zat perangsang tumbuh seperti etilen dapat merangsang jaringan buah pisang mengeluarkan etilen (Prabawati dkk., 2008). Ridhyanty dkk. (2015) dalam penelitiannya pada buah pisang barangan, juga menyatakan bahwa adanya peningkatan konsentrasi etilen secara eksogen dapat meningkatkan kandungan vitamin C. Utami dkk. (2014) melaporkan bahwa penggunaan etilen pada pisang raja menyebabkan kandungan vitamin $\mathrm{C}$ yang paling tinggi yaitu $8,51 \mathrm{mg} / 100 \mathrm{~g}$. Murtadha dkk., (2012) juga menguatkan tentang pengunaan etilen dapat mempengaruhi kandungan vitamin $\mathrm{C}$ pada buah pisang barangan.

Kandungan vitamin $\mathrm{C}$ pada buah pisang nangka yang diperam menggunakan daun kakao lebih tinggi dibandingkan penggunaan 2 jenis daun lainnya. Penggunaan dosis daun yang tepat juga sangat bepengaruh pada berlangsungnya pematangan dosis yang berlebih dapat memicu terjadinya respirasi anaerob sehingga terjadi penurunan kandungan vitamin $\mathrm{C}$ (Prabawati dkk., 2008).

Perlakuan lama pemeraman 6 hari menunjukkan bahwa kandungan vitamin $\mathrm{C}$ tertinggi $(66,01 \mathrm{mg} / 100 \mathrm{~g})$ pada pisang nangka (Gambar 2). Pemasakan yang terjadi pada buah akan berdampak pada turunnya kadar asam - asam organik. Penurunan asam organik diakibatkan oleh konversi asam organik menjadi gula. Proses tersebut akan dialami buah terkecuali pada pisang dan nanas, dimana saat pisang mengalami pematangan hingga mencapai masak penuh maka vitamin C akan terus meningkat (Utami dkk., 2014). Saat pemeraman 9 hari, kandungan vitamin $\mathrm{C}$ menurun dikarenakan pisang mengalami proses penuaan dan pembusukan. Menurunnya kandungan vitamin $\mathrm{C}$ dikarenakan adanya proses oksidasi dan biosintesis vitamin C. Vitamin $\mathrm{C}$ akan berubah menjadi L-dehidroaskorbat dan perubahan selanjutnya menjadi L-diketogulonat. Saat proses inilah vitamin $\mathrm{C}$ akan menjadi padatan terlarut sehingga kandungannya pada buah menurun (Almatsier, 2006).

\section{SIMPULAN}

Cara pemeraman menggunakan daun kakao dan etilen $0,5 \%$ mempengaruhi kematangan buah pisang nangka. Etilen $0,5 \%$ dapat meningkatkan skor pematangan buah pisang nangka dan kandungan vitamin $\mathrm{C}(74,56 \mathrm{mg} / 100 \mathrm{~g})$. Daun kakao berpengaruh pada peningkatan skor pematangan, kadar gula tereduksi $(410,66 \%)$ serta kandungan vitamin C $(67,55$ $\mathrm{mg} / 100 \mathrm{~g}$ ). Semakin lama pemeraman dapat meningkatkan skor pematangan buah pisang nangka dan meningkatkan kadar gula tereduksi sebelum buah mengalami pembusukan. Sedangkan kandungan vitamin $\mathrm{C}$ meningkat hingga pematangan maksimum, kemudian menurun saat menuju proses pembusukan.

\section{UCAPAN TERIMAKASIH}

Ucapan terimakasih kepada seluruh laboran Lab. Analisis FTP Unud yang senantiasa memberi pengarahan saat penelitian dilakukan serta Dr. Dra. Ni Putu Adriani Astiti, M.Si, Ir. Ida Ayu Astarini M.Sc., Ph.D dan Ir. Made Pharmawati, M.Sc., Ph.D atas masukan dan saran yang diberikan.

\section{DAFTAR PUSTAKA}

Almatsier, S. 2006. Prinsip Dasar Ilmu Gizi, Edisi ke-6. Gramedia Pusaka Utama: Jakarta.

Anam, M. F. 2011. Pengaruh Cara Dan Lama Pemeraman Terhadap Kadar Gula Reduksi, Kandungan Vitamin A, Kadar Air Dan Tekstur Buah Pisang Raja Nangka (Musa paradisiaca L.). (Skripsi). Jurusan Biologi. Fakultas Sains dan Teknologi. Universitas Islam Negeri (UIN) Maulana Malik Ibrahim Malang. 
Apandi, 1984. Teknologi Buah Dan Sayur. PT. Rineka Cipta. Yogyakarta.

Dewi, E. K. 2010. Analisis Vitamin C dan Kadar Gula Total pada Dua Varietas Buah Mangga (Mangifera indica L.) dengan Lama Penyimpanan yang Berbeda. (Skripsi). Jurusan Biologi. Fakultas Matematika dan Ilmu Pengetahuan Alam. Universitas Udayana. Tidak dipublikasikan.

Fitriningrum, R., Sugiyarto dan A. Susilowati. 2013. Analisis Kandungan Karbohidrat pada berbagai Tingkat Kematangan Buah Karika (Carica pubescens) di Kejajar dan Sembungan, Dataran Tinggi Dieng, Jawa Tengah. Bioteknologi 10 (1): 6-14.

Rahim, I., T.Kuswinanti, L. Asrul dan B. Rasyid. 2015. Potensi Jamur Pelapuk dalam Mendekomposisi Limbah Kulit Kakao. Prosiding Seminar Nasional Mikrobiologi Kesehatan dan Lingkungan. Universitas Islam Negeri Makasar.

Ridhyanty, S. P., Elisa, J., dan Linda, M. L. 2015. Pengaruh Pemberian Ethepon sebagai Zat Perangsang Pematangan terhadap Mutu Buah Pisang Barangan (Musa paradisiaca L). Jurnal Rekayasa Pangan dan Pertanian 3 (1) :1-13.

Kader, A. A. 2002. Postharvest Technology of Horticultural Crops. 3rd edition Cooperative Extension. Division of Agriculture and Natural Resources. University of California. Oakland. California.
Mahapatra, D., S. Mishhira dan N. Sutar. 2010. Banana and Its by Product Utilisation: an Overview. Journal of Scientific and Industrial Research 69: 323-329.

Murtadha, A., E. Julianti dan I. Suhaidi. 2012. Pengaruh Jenis Pematangan terhadap Mutu Buah Pisang Barangan (Musa paradisiaca L.). Jurnal Rekayasa Pangan dan Pertanian 1: 41-56.

Prabawati, S., Suyanti dan Setyabudi, D.A. 2008. Teknologi Pasca Panen dan Teknik Pengolahan Buah Pisang. Badan Penelitian dan Pengembangan Pertanian.

Pujimulyani, D. 2009. Teknologi Pengolahan Sayur - Sayuran dan Buah - Buahan. Graham Ilmu: Yogyakarta.

Siagian, H.F. 2009. Penggunaan Bahan Penjerap Etilen pada Penyimpanan Pisang Barangan dengan Kemasan Atmosfir Termodifikasi Aktif. (Skripsi). Universitas Sumatera Utara.

Utami, S., J. Widiyanto dan Kristianita. 2014. Pengaruh Cara dan Lama Pemeraman terhadap Kandungan Vitamin C pada Buah Pisang Raja (Musa paradisiaca L). Jurnal Edukasi Matematika dan Sains. 1(2): 42 - 47.

Wina, E. 2001. Tanaman Pisang sebagai Pakan Ternak Ruminansia. Wartazoa 11(1): 20-27.

Yulianingsih dan I.M.Dasuki. 1989. Pemeraman Buah Pisang dengan Daun Gamal (Gliricidia sapium). Penelitian Hortikultura 3(3): 94-104.

Zuhairini. 1997. Budidaya Pisang Raja. Trubus Agrisarana. Surabaya. 